Thts:

Author(s):

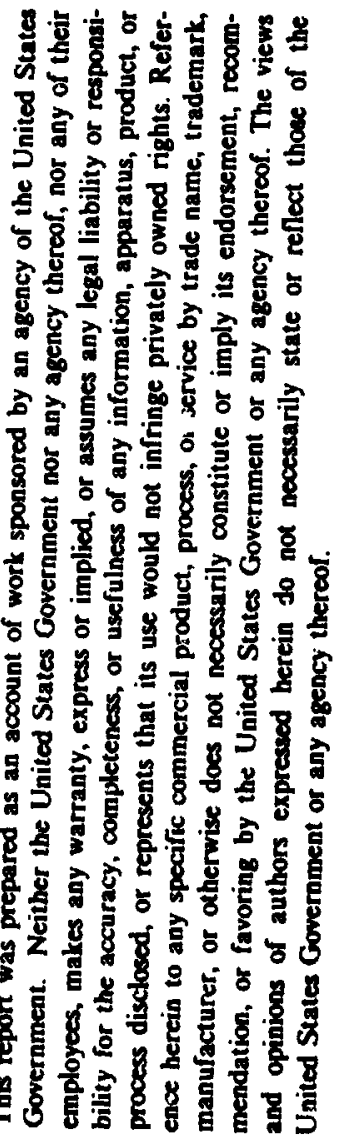

Development of a RAMI Program for LANSCE Upgrade
K. C. D. Chan
R. L. Hutson
R. J. Macek
P. J. Tallerico
C. A. Wilkinson

1995 Particle Accelerator Conf. and Intl. Conf. on High-Energy Accelerators

May 1-5, 1994

Dallas, Texas

\section{4}

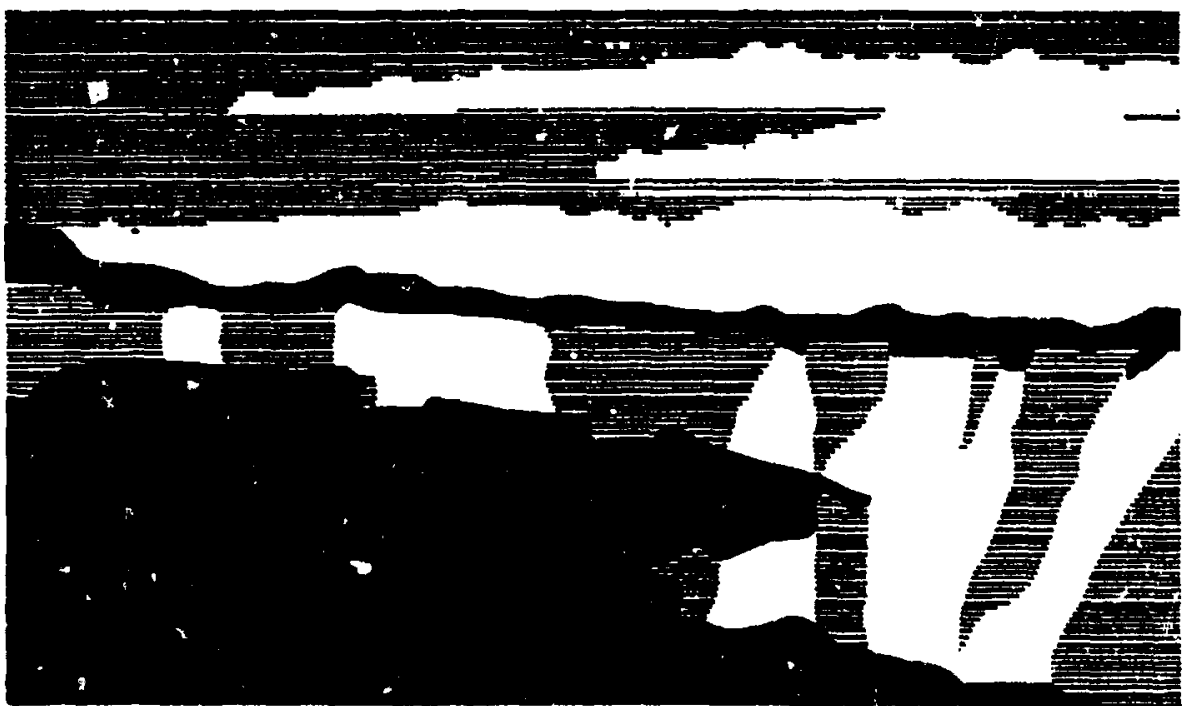

NATIONAL LABORATOR

Los Alemos National Laboratory, an aflirmative acionvequal opportunity employer, is operated by the Univerely of Calliornia for the U.S. Department of Eneroy Under contract W-7405-ENG-30. By ecceptence of this article, the publisher recognizes that the U.S. Government reteine a nonexclualve, royalty-free license to publish or reproduce the publlshed form of this contribusion, of to dlow others to do so, for U.S. Covernment purposes. The Las Alamos National Laboratory requasts that the publisher identify this article as work performed under the c iapicese of the U.S. Depuriment of Enofgy. 


\title{
Development of a RAMI Program for LANSCE Upgrade
}

\author{
K. C. D. CHAN, R. L. HUTSON, R. J. MACEK,P. J. TALLERICO, AND C. A. WILKINSON \\ Los Alamos National Laboratory, Los Alamos, NM 87545
}

\begin{abstract}
Improvement of beam availability is a prime objective of the present LANSCE (Los Alamos Neutron Scattering Center) Ungrade. A RAMI (reliability, availability, maintainability, and inspectability) program is being developed to identify the most cost-effective improvements to achieve the availability goal. The beam-delivery system is divided into subsystems appropriate for the modeling of availability. The availability of each subsystem is determined from operation data and assessment of individual component designs. These availability data are incorporated in an availability model to predict the benefit of improvement projects to achieve costbenefit prioritization. Examination of the data also identifies a comprehensive list of factors affecting availability. A good understanding of these factors using root-cause analysis is essential for availability improvement. In this paper, we will describe the RAMI program and the development of the availability model.
\end{abstract}

\section{Introduction}

Presently, the Los Alamos Meson Physics Facility (LAMPF) is undergoing an availability upgrade [1] so that the accelerator can become a reliable driver for the Los Alamos Ncutron Scaltering Center (LANSCE). The availability goal is to operate LANSCE at $100 \mu \mathrm{A}$ with better than $85 \%$ availability over an operation period of eight months per year. Because of the durations of neutronscattering experiments, it is important to keep the downtim:s longer Uhan 8 hours to less than $10 \%$ and those longer than 24 hours to less than $1 \%$. A RAMI (reliability, availability, maintainability, and inspectability) program is being developed to insure that the upgrade is done in a cost-effective fashion. It will be used to plan, monitor, predict, and improve availability of the LANSCE beam-Jelivery system.

The RAMI Program is also being used to plan the maintenance and upgrade of LAMPF in the next five years. The purpose is to systematically replace obsolete and unreliable equipment from the LAMPF beam-delivery system so that the Facility can extend its lifetime for another 20 years.

RAMI works have been carried out previously at LAMPF. In the late 70's, a RAMI program was instituted to bring the availability from $65 \%$ to $80 \%$ [2]. The system tracked the failures of equipinent and the repair cost. The progran was later tenninated. A review of the recent RAMI works at LAMPF have been given by Macek in Ref. 3. In 1994, a pilot Project, Development of a Reliability, Availability, Maintainability, and Inspectability Model for High Powe: Accelerators, was funded for a year. A report is being prepared [4]. The work described in this paper is the continuation of the recent RAMI works.

\section{RAMI Program}

The RAMI Program has three parts: Availability Model, Root-Cause Analysis, and Maintenanc Policy. The beam-delivery system is divided ino subsystems and the subsystems are collections of individual components. The Availability Model uses a database that contains the availability data of all the components to predict the availability of the beamdelivery system and the subsystems. The prediction is made using a set of assumptions, for example, the distribution of failures and repairs. These assumptions are part of the Ava''ability Model. The corrmonly used assumptions ' an be found in Ref. [3] and [5]. The Availability Model should reproduce the observed availability and will be able to predict the gain in availability of improvements and the costeffectiveness. The availability model will also be used to identify the low-availability subsystems so that a Root-Cause Analysis can be done on the subsystems. The Root-Cause Analyris is an indepth analysis of the nerformance of a subsystem and suggests improvements. Maintenance Poiicy helps us to maintain the performance of the accelerator.

\section{Availability Model}

The database used by the Availability Model is assembled by first listing all the components in the beam-delivery systern. Examples of components are po" er supplies, klystrons, and beam-pnsition monitors. These componel:s are grouped into subsystems. Subsystems are usually groups of components with similar locations and purpose along the beam-delivery system. They are grouped with enough components to have sufficient availability statistics. Examples of subsystems are injector, PSR (Proton Stomge Ring), and Neutron Prouluction Target. Components are also assigned function designators according to their functions. Examples of function designaicrs are magnet, water, and vacuum. Both subsystem and function designators are needed to facilitate snrting available information in the database so that the information is presented in a more digestible forn. For exa. iple, one can easily find the availability of the water system in PSR by selecting 
all the components that have subsystem designator of PSR and function designator of water and summing their availabilities.

After listing all the components, availability data of these components were collected. These availability data are in the form of MTF (mean time between failures) and MTR (mean time of repairs). They are derived from experience and assessment of designs. At this point, the assembly of the databa. is complete and predictions of availability of subsystem ran be made in conjunction with assumptions made in the Availability Model.

The present Availability-Model database for the beam-delivery system has a total of 385 components. These are actually component types because similar components are counted as one component. These components are separated into nine subsystems. Subsystem names are given in Table !. There are 14 function designators (Table 2).

The Availability Model can be henchinarked by comparing its availability precirtion with observed availability for subsystems. The observed availabilities of subsysterıs are provided through operation logs where operators record the times and causes of component failures and repairs. Presently. the operators are recording the failed subsystem and the failure mode in a specified format. The subsystem and function designators have been chosen to correlate with that format so that data can be easily derived from the operator $\log$ to compare with the Availability Model. Figure 1 shows the observed distribution of time-between-failures for subsystems: injector and Sector A during the operation in 1994. These data were used to drive the availability, MTF, and MTR for the subsystems.

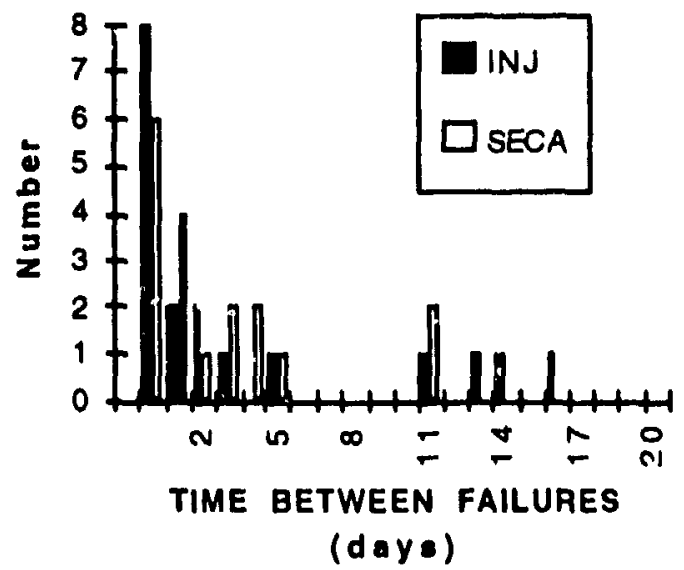

Fig. 1 Distribution of time-between failures

Table di List of subsystems

$\begin{array}{lll}\text { Injector } & \text { Sector A } & \text { Sector B-H } \\ \text { Switchyard } & \text { Area A } & \text { Line D } \\ \text { PSR } & \text { Target } & \text { WNR }\end{array}$

Table 2: List of funcuons

$\begin{array}{lll}\text { Aperture } & \text { Beamline } & \text { Controldata } \\ \text { Diagnostic } & \text { Facility } & \text { Magnet } \\ \text { RF } & \text { Safety } & \text { Source } \\ \text { Structure } & \text { Timing } & \text { Vacuum } \\ \text { Water } & \text { Misc. } & \end{array}$

The PSR Pulsed Power System has been studied before using an Availability Model and is described here as an example [6]. The complete system was divided into four subsystems: switchyard k cker magnets (LDKIs), PSR injection linekicker magnet (RIKI), the $2.8 \mathrm{MHz}$ RF beam buncher (SRHM), and the electromagnetic extraction kickers (SRFK). Table 3 sizows the part of the database used for RIKI. The availabilities predicted using the database for the subsystems and complete system were compared to observed availabilities from operato:'s logs (Table 4).

\section{Root-Cause Analysis}

The Availability Model and the observed data can identify the low-availability subsystem. A RootCause Analysis is needed to identify the failure modes so that improvernents can be made. These improvements include a better design, preventive maintenance, and monitoring programs. Assuming these improvements, new MTF and MTR data can be generated and used in the Availability Model to predict the improved availability. Examples of RootCause Analysis can be found in Ref. [3].

\section{Maintenance Policy}

Maintainability and inspectability will be addressed with Maintenance Policy. Regular monitoring and maintenance are needed to reduce failure and downtime. In older facility like LAMPF, a sustained replaceinent. program is also needed for equipinent that has moving parts. Because of budgetary constraints, the replacement program is not in place yet. A conscious effort has besn made, insteal, to keep an inventory of spare parts of longdowntime components. A record of these spare parts will be incorporated in the Availability-Model database. In the future, component maintainability, monitoring, and inspectability will also be incorpurated iil the designs of components.

\section{Summary}

A RAMI Program is being developed to insure that the upgrade of LANSCE will be done in a cost- 
effective manner. The Availability Model is being assembled and complemented with Root-Cause Analysis and Maintenance Policy.

\section{Acknowledgment}

This work is supported by Los Alamos Naiional Laboratory Institutional Supporting Research, under the auspices of the United States Department of Energy

\section{References}

[1] LANSCE 1.5 Ungrade

[2] R. A. Jameson, R. S. Mills, M. D. Johnston, "Management Information for LAMPF", LA5707-MS Informal Report, UC-28, LASL, August 1974.
[3] Report of the Committee on a TA-53 Upgrade, Chapler 5, Arch Thiessen (Chairman), Los Alamos National Laboratory Report.

[4] C. Wilkinson, Development of a Reliability, Availatility, Maintainability, and Inspectability Model for High Power Accelerators, Los Alamos National Laboratory LDRD Report, in preparation.

[5] E. E. Lewis, Introduction to Reliability Engineering, published by John Wiley \& Sons, 1987.

[6] R. Hutson, Preliminary Availability Analysis of PSR/LANSCE Pulsed Power Systems (For Five-Year Peric $\mathrm{J}$, 1988-1992, Cycles 51-62),

Los Alamos National Laboratory, AOT-2

Technical Notes, Sept. 30, 1994.

Table 3: Availability-Model Datahase for RIKI

\begin{tabular}{|c|c|c|c|c|c|c|}
\hline Subsystem & Component & Function & MTF (days) & MTK (h) & Spares & Avail. \\
\hline 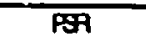 & Magnet: & & & & & \\
\hline PSP & Magnel current connections & magnel & 20000 & 6 & Parts & 0.999988 \\
\hline $\bar{F}$ & Coils & magnet & 10800 & 340 & 1 & 0.998690 \\
\hline PSA & rharging system: & & & & & \\
\hline PSP & PS,Sorenson DCR 600.8T & magnet & $360 \mathrm{C}$ & 4 & 1 & 0.999954 \\
\hline F्ञ & PS, Christie 1C015-600EBBX4S & magnel & 3600 & 8 & some perts & 0.999907 \\
\hline$\overline{F P}$ & Modulator: & & & & & \\
\hline$\overline{P B R}$ & Resonate Charge SCR & magnel & 3600 & 8 & 3 & 0.899907 \\
\hline$\overline{P S}$ & Zener Diode Assembly & magnet & 1000 & 5 & 3 & 0.999792 \\
\hline PR & Charge Recover SCR & magnet & 3600 & 8 & 3 & 0.998907 \\
\hline FR & Freewheel SCR & magnel & 3800 & 8 & 3 & 0.999907 \\
\hline$\overline{R A}$ & Transfer Chassis & magnet & 1800 & 16 & 0 & 0.999630 \\
\hline FrR & Controle and Interlocks: & & & & & \\
\hline RA & RIK101 Run Permil & salety & 3600 & 1 & Parts & 0.999988 \\
\hline PG & NIM Crale & salely & 1800 & 8 & Pants & 0.999815 \\
\hline$\overline{P E R}$ & Short Nim Crale & saloly & 1800 & 8 & Pants & $0 . \overline{999815}$ \\
\hline FA & Computer Interlace: & & & & & \\
\hline F & CAMAC & conlrol/dala & 7300 & 4 & $\bar{i}$ & 0.099977 \\
\hline & & & & & Sub. Avail & 0.897280 \\
\hline
\end{tabular}

Table 4: Comparison of observed availability and availability predicted with Availability Model_Allavailabilities are in percentages.

\begin{tabular}{|c|c|c|c|c|c|}
\hline & LDKI & RIKI & SRIIM & SRFK & Total \\
\hline Ohserved & 99.1 & 98.8 & 96.5 & 97.8 & 92.4 \\
\hline Predicted & 97.7 & 99.7 & 98.6 & 98.4 & 94.6 \\
\hline
\end{tabular}

